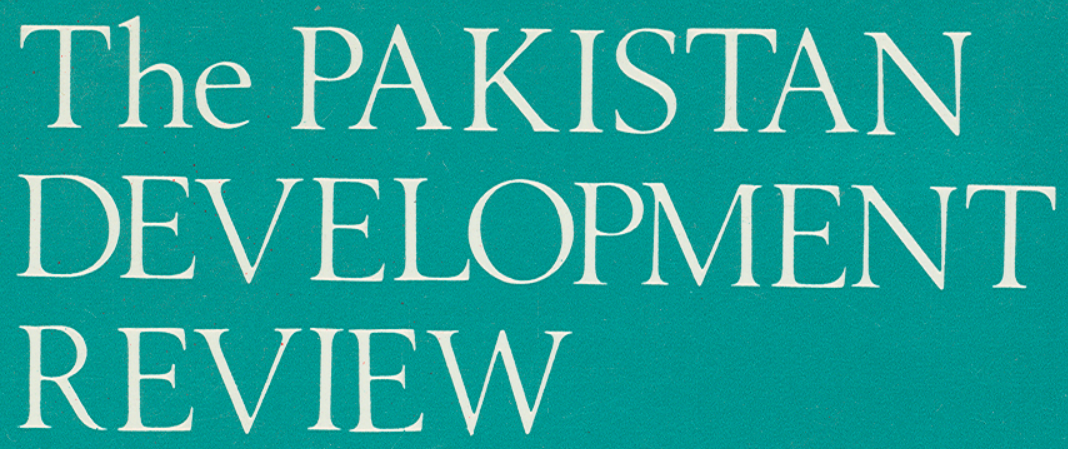

An International Journal of Development Economics

Who Gets Primary Schooling in Pakistan:

Inequalities among and within Families

Zeba A. Sathar and Cynthia B. Lloyd 103

The Demand for Financial Assets in Pakistan

Sajjad Akhtar and Sajid Manzoor 135

Market Structure and Inter-industry

Profit Differences in Taiwan

Cheng-chung Lai 147

REVIEW ARTICLE

Long-term Development of Small-scale Industries

in Relation to Economic Development:

Looking for General Propositions

Tulus Tambunan 165

BOOK REVIEWS

Naqvi, Syed Nawab Haider. Development Economics:

A New Paradigm

Lawrence R. Klein 191

Pakistan, Ministry of Finance, Revenue and Economic Affairs.

Report of Prime Minister's Task Force on Agriculture

M. Ghaffar Chaudhry 194

Dennis Kux. Estranged Democracies: India and the

United States 1941-1991

Khwaja Sarmad 200

Philip G. Pardey, Johannes Roseboom and Jock R. Anderson (eds).

Agricultural Research Policy: International

Quantitative Perspectives

Sohail Jehangir Malik 202

BOOK NOTES 206 


\section{PAKISTAN INSTITUTE OF DEVELOPMENT ECONOMICS \\ Quaid-i-Azam University Campus \\ Post Box 1091, Islamabad}

(Pakistan)

The Institute, established by the Government of Pakistan in 1957, is an autonomous research organization devoted to carrying out theoretical and empirical research on development economics in general and on Pakistan-related economic issues in particular. Besides providing a firm foundation on which economic policy-making can be based, its research also provides a window through which the outside world can see the direction in which economic research in Pakistan is moving. The Institute also provides in-service training in economic analysis, research methods, and project evaluation.

\section{BOARD OF GOVERNORS}

Syed Nawab Haider Naqvi, Director

Muhammad Afzal

Rafiq Ahmed

Qazi M. Alimullah

H. U. Beg
M. Fazil Janjua

Aftab Ahmad Khan

G. J. Pareshan Khattak

Abdul Hameed, Secretary

INTERNATIONAL ADVISORY BOARD

Henk C. Bos

Ansley J. Coale

Gamani Corea

Just Faaland

Albert O. Hirschman
Lawrence R. Klein, Nobel Laureate

Janos Kornai

E. Malinvaud

Gustav Ranis
Ashfaq Mahmood

Mian M. Nazeer

M. M. Usmani

Muhammad Yaqub

COUNCIL OF SENIOR FELLOWS

Muhammad Afzal

Rafiq Ahmed

Mahfooz Ali

H. U. Beg

M. Fazil Janjua
Shoaib Sultan Khan

Ghulam Hussain Khaskhelly

M. M. Malik

Mian M. Nazeer
Lloyd G. Reynolds

Paul Streeten

J. Tinbergen, Nobel Laureate

Robert Triffin

Winfried von Urff
Asghar Qadir

Ghulam Rasul

M. Nazir Romani

Agha Shahi

Shukurullah 


\title{
Who Gets Primary Schooling in Pakistan: Inequalities among and within Families
}

\author{
ZEBA A. SATHAR and CYNTHIA B. LLOYD
}

The chances of Pakistani children's entering school and completing the primary level are extremely low even in comparison with the relatively poor situation in other South Asian countries. This paper uses the 1991 Pakistan Integrated Household Survey to explore some of the determinants of parents' decisions about their children's schooling, giving particular attention to factors at the household and community levels.

The results indicate that inequalities across households provide a major explanation for variations among children in primary schooling levels. Even the basic decisions relating to children's entry into school and completion of the primary level are largely determined by parents' education, particularly that of mothers, and household income. Primary school is not compulsory and even attendance at public school requires substantial monetary outlays. With only a small percentage of school-age children in Pakistan having mothers with any education or parents with sufficient income, the cycle of poverty and unequal opportunity is perpetuated. The accessibility of "appropriate" single-sex schools and the availability of quality schools are important additional factors in children's schooling outcomes, particularly for girls in the rural areas.

The findings also portray inequatities among children within the same household. The most striking of these are differences between boys and girls. Also larger numbers of siblings reduce the probability of primary school completion for children in the urban areas and significantly reduce average educational expenditures, suggesting an emerging quality-quantity trade-off between fertility and education. The paper concludes by recommending a substantially increased government commitment to primary education, with particular emphasis on the needs of girls. Expected gains would include greater gender equality, a substantial improvement in human development, and, possibly, a decline in fertility.

Pakistani children face relatively poor odds of ever entering school and even worse chances of completing the primary level. The situation is alarming even when compared to the disappointing educational achievements of other South Asian countries [Khan (1991)]. The negative outcomes of this neglect of child schooling are far-reaching and clear: the history of under-investment in education has not only been faulted for retarding economic growth rates and limiting human development,

Zeba A. Sathar is Chief of Research at the Pakistan Institute of Development Economics, Islamabad and Cynthia B. Lloyd is Senior Associate and Deputy Director, Research Division, the Population Council, New York.

Authors' Note: We acknowledge with appreciation the support of Valerie Kozel and the access to the data provided by the World Bank, as well as the helpful comments of David Shapiro and John Bongaarts and the able computer assistance of Jin Wei, who created the child files and is responsible for all statistical tabulations. We are also grateful to an anonymous referee for his very useful comments. 
but more recently has been identified as a major obstacle to reducing rapid population growth rates [Summers (1992)]. What remains unanswered, however, is whether the present situation is attributable entirely to the government's underinvestment in education, which could be remedied through increasing the number and quality of schools and teachers, or whether other forces are at work-some possibly also linked to public policy-that make parents reluctant, even when schools are available, to send some or all of their children to school.

This paper examines the factors behind primary school attendance in Pakistan and addresses some of these questions by looking at differential educational participation of children across and within households. We analyse the determinants of current primary school enrolment and completion among children in Pakistan as well as the level of parental expenditures on children enrolled at the primary level. The study is based on the 1991 Pakistan Integrated Household Survey (PIHS), which includes a national sample of 4711 households [World Bank (1992)]. This survey is rich in a number of ways: it includes complete demographic, social, and economic data on all household members; it contains a full birth history for reproductive-age women; and it provides information by community on the availability of schools for boys and girls by type of facility.

We begin with a discussion of public policy on education, followed by a description of the key features of the current situation with respect to primary schooling in Pakistan. The next section discusses the likely determinants of parents' decisions about their children's schooling, drawing on previous evidence from Pakistan wherever available. The main findings of this analysis are presented in the fourth section, which highlights the results of a multivariate analysis of schooling determinants, focusing on some of the major factors explaining inter- and intrafamily differences among children in schooling outcomes. Throughout the analysis, results are presented separately for boys and girls and for urban and rural areas. ${ }^{1}$

\section{PRIMARY SCHOOLING: \\ A QUESTION OF MISPLACED PUBLIC POLICY?}

For some time, there has been strong evidence in the development and education literatures that the social rates of return to broad-based educational investments at the primary level are high [Psacharopoulos (1985); Schultz (1991); in particular Alderman et al. (1992) for rural Pakistan]. ${ }^{2}$ These returns are typically measured in

${ }^{1}$ While 72 percent of Pakistan's population lives in rural areas [NIPS (1992)], urban and rural areas were sampled equally in the PIHS so that the presentation of nationally representative estimates would require the use of weights. Because the situation in urban and rural areas differs greatly, we considered it more illuminating to present the results separately.

${ }^{2}$ The estimated social rates of return to targeted investments in improving the performance of even low-quality primary schools are high regardless of gender or region. 
terms of net increases in income or output. It is surprising, then, that despite low levels of investment in the education sector, Pakistan has achieved rapid growth in per capita income. Recent years have seen an increased realisation that the concept of development has to shift from an emphasis on increases in average per capita income to an emphasis on human development [UNDP (1990)]. The central idea of the human development approach is one of valuing human capabilities per se rather than valuing the extent of their command over resources as a means to an end [Anand and Ravallion (1993)]. This new approach provides an even greater rationale for pursuing investments in education than that made previously on pure income grounds and calls attention to achievements such as those of Sri Lanka and the State of Kerala in India, both of which have relatively more educated and healthy populations despite modest-to-low levels of income.

Adding a demographic perspective to the perspectives already discussed, it is clear furthermore that levels of fertility-which are directly linked with population growth rates and thus a society's capacity for achieving further improvements in human development-are strongly influenced by primary enrolment levels. This is not only because of the well-documented fertility differentials between mothers with little or no education, and those who have completed primary schooling [United Nations (1987) and Rodriguez and Aravena (1991)], but also because of the wellknown negative relationship between the rising costs of children and the parental demand for them [Caldwell (1980)].

Despite the strength of the foregoing arguments for promoting primary education, Pakistan has had an abysmal record in the education sector over the last four decades. The government's failure to guarantee children, particularly girls, the minimum of a primary education [Siddiqui (1991)] has only recently been recognised as a serious shortcoming of Pakistan's development policy. The most prominent evidence of this neglect, of course, is low governmental expenditures on education. The government's financial commitment to education remains distressingly small-2.6 percent of central government expenditure was devoted to education in 1987 as compared to 10.6 percent in nearby Bangladesh [Khan (1991)]. Education has historically been a low priority. The government's development strategy has instead been tilted in favour of spending on industry, infrastructure, and defence. Furthermore, education budgets have usually favoured higher education instead of developing a broader base at the primary level. Within the government's education budget, the proportion of total expenditures allocated to primary education was consistently below 20 percent until 1978. Since then it has risen steadily, reaching 45 percent in the recent 1988-93 period [Khawja (1989)]. Not only has education always received low priority in development planning, but, during several Development Plan periods, actual expenditures have been drastically reduced below levels originally budgeted in favour of defence spending. There is ample evidence 
that actual expenditures have often fallen short-in the more recent Fifth and Sixth Five-Year Plans by as much as $60-70$ percent of original allotments [Khawja (1989)] ${ }^{3}$ In addition, continued rapid population growth, exceeding 3 percent per year, ${ }^{4}$ has made it more and more difficult to provide sufficient schools and teachers for increasing school-age cohorts. The result is poor quality schools and an inadequate supply of schools, particularly in rural areas.

But even where schools are available, not all children attend them. It is apparent that many parents choose not to enrol their children, allow them to attend school only intermittently, or withdraw them prior to the completion of the primary level. Children usually contribute to household labour or perform critical chores that make it difficult for parents to spare them for school, particularly after they reach early adolescence. At the same time, the majority of households in Pakistan face financial constraints that affect the affordability of schooling-because of low incomes and the non-negligible out-of-pocket costs of even public schooling at the primary level. Therefore, they do not have a real choice to make in terms of sending all their children to school. Financial constraints are compounded when there are many children to educate; as a result, parents may be forced to determine how many children they can afford to educate.

Because of steadily declining infant and child mortality and the persistence of high fertility over several decades, completed family size has actually been increasing, implying a growing educational burden for many Pakistani parents. The mean number of living children per woman among those who have completed their childbearing (ages 40-49) has risen from 4.9 in 1975 to 5.5 in 1990 [United Nations (1987); NIPS (1992)]. ${ }^{5}$ Furthermore, given the limited labour market opportunities in rural areas-particularly for girls-the future returns to primary school completion may seem small to many Pakistani parents in relation to current costs and household budget constraints.

Thus public policy, had it been historically oriented more towards providing cheaper, more widespread, and better educational opportunities, would at least have reduced some of the constraints on parents' choices about sending their children to school. At present, however, since primary schooling is far from compulsory and not all children are guaranteed access to school, decisions about schooling may be

${ }^{3}$ In the Fifth Plan period (1978-83), the allocation to education was 10,281 million rupees, while only 5,005 million was actually expended. In the Sixth Plan period (1983-88), 18,830 million rupees was allocated and only 13,430 million were expended.

${ }^{4}$ While recent data [NIPS (1992)] provide unsubstantiated hints of fertility decline, fertility in Pakistan still remains high ( 5.4 births per woman for 1985-90, as estimated by the recent PDHS survey) and the use of modern contraceptive methods remains unusually low (11 percent of currently married women).

${ }^{5}$ Sibsizes remain high in both urban and rural Pakistan, with children aged 10-14, according to the PIHS, having on average 5.2 and 5.4 living siblings, respectively. 
affected not only by considerations of family resources and household work requirements but also by school availability and quality. Although differences across households in social, economic, and community circumstances are likely to explain much of the variation in children's schooling, yet differences among children within the same family are expected to be important as well. This is apparent from the large gap between boys and girls in the enrolment and completion rates. Other factors that might be expected to contribute to intra-family inequality in children's schooling levels are birth order and number of siblings.

\section{GETTING TO PRIMARY SCHOOL: VARIATIONS BY RESIDENCE AND DIFFERENCES IN ACCESS AND COSTS}

Primary school enrolment ratios have risen gradually from 40.4 percent in 1977-78 to 49.3 percent in $1989-90$ (see Table 1 ) ${ }^{6}$ Disparities by sex, which have always been large, appear to have widened over time. Participation rates for boys have risen from 52 to 64 percent as compared to a rise from roughly 27 to 34 percent for girls.

Table 1

Enrolment Ratios in Primary Schools 1977-90

\begin{tabular}{lccc}
\hline & $1977-78^{1}$ & $1982-83^{2}$ & $1989-90^{2}$ \\
\hline Total & 40.4 & 44.0 & 49.3 \\
Girls & 27.4 & 30.0 & 33.8 \\
Boys & 52.2 & 60.0 & 64.1 \\
\hline
\end{tabular}

Sources: 1. [Khan, Mahmood, and Siddiqui (n.d.), Table IV-I, p. 48].

2. [Mahmood and Zahid (1992)].

The most critical transition in Pakistan's education system-in particular for girls-is entry into school. Table 2 shows the proportion of children of ages 7-14

${ }^{6}$ Here we present the enrolment ratios computed, using numbers of children actually enrolled as the numerator and children aged 5-9 (calculated on the basis of projected growth rates) as the denominator for primary schools. These ratios can be considered imprecise because of the considerable variation in Pakistan in the ages when children begin to attend and complete primary school. Published UNESCO data on primary enrolment ratios [UNESCO (1992)] actually imply a decline in gross primary enrolment ratios in the late 1980 s. These data appear to be in error, however, because enrolment ratios calculated directly from the actual numbers enrolled and the number of school-age children suggest higher ratios in recent years and continued slow improvement.

${ }^{7}$ This age group has been chosen for the analysis of primary school enrolment because 73 and 79 percent of children attending primary school in urban and rural areas, respectively, fall within this age range. Furthermore, the average age of children attending level 5 (the last year of primary) is just above 10 , suggesting that entry by age 7 is typical. 
Table 2

Percent of Children Aged 7-14 Ever Attending School by Urban-Rural Residence and Sex

\begin{tabular}{lcc}
\hline & Girls & Boys \\
\hline Pakistan & & \\
Urban & 72.9 & 82.9 \\
Rural & 39.7 & 73.8 \\
Punjab & & \\
Urban & 81.4 & 86.4 \\
Rural & 49.2 & 79.8 \\
Sindh & & \\
Urban & 74.8 & 80.6 \\
Rural & 29.2 & 62.0 \\
North-West Frontier Province & \\
Urban & 59.6 & 86.4 \\
Rural & 37.9 & 79.5 \\
Balochistan & & \\
Urban & & 62.1 \\
Rural & 38.0 & 61.7 \\
\hline Source: & 28.3 &
\end{tabular}

Source: [PIHS (1991)].

ever attending school in 1990-91 by sex in urban and rural areas, for all four provinces and for the country as a whole. Looking first at the national data, the proportions ever enrolled are lower in rural areas and for girls. Among children of these ages, 73 percent of the girls have been to school in urban areas as compared to 40 percent in rural areas. For boys, 83 percent have been enrolled in urban areas as opposed to 74 percent in rural areas. The result is an enrolment rate for rural girls that is less than half the rate for urban boys. On the other hand, the sex differential in enrolment in urban areas is only 10 percentage points.

With respect to provincial differences, the highest enrolment rates and the lowest sex differentials are found in the Punjab, but even here the enrolment of girls is 30 percentage points below that of boys in rural areas. Children appear to fare worse in Balochistan than in any other province, although urban/rural differentials are small. Sex differentials in urban enrolments are relatively small in the Punjab and Sindh but rise to 24-26 percentage points in Balochistan and the NWFP. Among rural children, the proportions of girls ever attending school vary from 28 
percent in Balochistan to 49 percent in the Punjab, and for boys from 62 percent in Balochistan to 80 percent in the Punjab.

While entering school is crucial, completing primary school (through grade 5) is probably an even more critical point of transition for children in Pakistan. This stage could occur as early as age nine, but typically occurs later among those who do not drop out as a result of late entry and grade repetition [Siddiqui (1991); Mahmood and Zahid (1992)]. The first panel of Table 3 shows variations in the proportion of children completing primary school by urban/rural residence for all boys and girls aged 10-14. While some children in these age groups will finish at later ages, this provides a good measure of primary school performance in Pakistan as it encompasses the ideal age of completion (10) and the normal range of ages for completion (10-14). ${ }^{8}$ Barely half of all urban boys complete primary school. The differences in completion rates are striking by sex and residence, but clearly girls in rural areas are most severely disadvantaged, with only 17 percent completing the primary level school. Completion rates for urban girls and rural boys are roughly similar-43-44 percent.

\section{Table 3}

Percent of Children Aged 10-14 Completing Primary School by Urban-Rural Residence and Sex

\begin{tabular}{lcccccc}
\hline & \multicolumn{2}{c}{ All Children } & & \multicolumn{2}{c}{ Children Ever Enrolled } \\
& Girls & Boys & & Girls & Boys \\
\hline Pakistan & & & & & \\
Urban & 43.9 & 52.1 & & 59.7 & 60.9 \\
Rural & 16.5 & 43.0 & & 42.8 & 52.7 \\
\hline
\end{tabular}

Source: [PIHS (1991)].

Completion of primary school, as measured on the basis of those who ever attended school, reflects differential patterns of grade completion and dropout after school entry. The second panel of Table 3 presents completion rates for children who have ever attended. In urban areas, roughly the same percent of ever-enrolled boys and girls aged 10-14 complete primary school (60-61 percent). In rural areas, the proportions completing primary school are lower: 43 percent for girls and 53 percent for boys. Once the analysis is restricted to children who have ever enrolled in school, gender differentials in primary school completion are only apparent in

${ }^{8}$ This age group was chosen for the analysis of primary school completion because about 80 percent of children completing grade 5 were aged $10-14$. 
rural areas, where they are not large (10 percentage points). Because fewer girls than boys go to school, the girls who do attend-particularly in rural areas-are a more selective group and, therefore, likely to have greater than average ability and motivation.

\section{Costs of Primary School}

Although public schools are heavily subsidised [Jimenez and Tan (1985)], children's education, even at the primary level, is by no means free for parents in Pakistan. Admission, registration, and tuition fees are required for attendance, and parents need to purchase uniforms as well. Many other expenditures may be optional, but nonetheless essential if children are to learn effectively. These include expenditures for books and supplies, meals, private tutors, and examination fees. As a result, expenditures vary from child to child even among those enrolled in public school. Parents also have the choice to enrol their children in a private school, which is significantly more expensive. In this analysis, we view the level of parental expenditures as a measure of the "quality" of their educational investment. The level of expenditure reflects not only the choice of type of school but also the purchase of "extras" that influence a child's progress from grade to grade.

Table 4 compares the average level of education expenditures for boys and girls aged 7-14 enrolled in primary school in urban and rural areas, with a further division by public and private facilities in urban areas..$^{9}$ There is indeed a contrast in the level of expenditure on various items for public and private school-the most important of which is tuition. Clearly private schooling is a much more expensive option and offers a very different quality of education. Even when comparing educational expenditures for public schooling, however, we find differences in levels of expenditure on non-tuition items, such as books, tutors, and meals, between children in urban and rural areas and between boys and girls. Public school tuition is in fact quite modest-amounting to $40-70$ rupees per child. However, the total cost of providing all supporting expenses for public school attendance is by no means trivial, amounting to 370 and 430 rupees for girls and boys, respectively, in rural areas. Differences in costs of schooling between boys and girls were statistically significant in both urban and rural areas. The total cost of public school is higher still in urban areas (550 to 680 rupees) and almost five times as high in urban private schools (1760-1950 rupees). The average annual per capita income in Pakistan in 1990-91 was 9000 rupees [NIPS (1992)], suggesting that the cost of primary schooling for one child in public school could represent 5-20 percent of a family's average resources per year.

${ }^{9}$ Private schools are not analysed separately in rural areas because so few rural children attend 
Table 4

Mean Education Expenditures in Rupees for Children Aged 7-14

by Urban-Rural Residence and Sex

(Based on Children Currently Attending Primary School)

\begin{tabular}{|c|c|c|c|c|c|c|}
\hline & \multicolumn{4}{|c|}{ Urban } & \multirow{2}{*}{\multicolumn{2}{|c|}{ Rural }} \\
\hline & \multicolumn{2}{|c|}{ Public } & \multicolumn{2}{|c|}{ Private } & & \\
\hline & Girls & Boys & Girls & Boys & Girls & Boys \\
\hline Tuition & 58 & 72 & 779 & 758 & 51 & 41 \\
\hline Uniforms & 155 & 188 & 236 & 283 & 146 & 161 \\
\hline Books/Supplies & 133 & 135 & 254 & 261 & 97 & 97 \\
\hline Transportation & 11 & 13 & 107 & 104 & 6 & 4 \\
\hline Private Tutor & 73 & 81 & 174 & 220 & 18 & 31 \\
\hline Examination Fees & 8 & 12 & 45 & 20 & 4 & 3 \\
\hline \multicolumn{7}{|l|}{ Other (Including } \\
\hline Meals, Room, etc.) & 100 & 119 & 174 & 229 & 36 & 63 \\
\hline Total* & 546 & 680 & 1759 & 1948 & 367 & 431 \\
\hline Number of Cases & 642 & 697 & 232 & 278 & 471 & 899 \\
\hline
\end{tabular}

Source: [PIHS (1991)].

*Sub-categories of expenditures do not add to the total because the number of missing cases varies by category. Thus, only households which reported on a particular category are represented on that line item.

\section{Access to Schools}

The result of low government outlays on education has been poor quality schools, a shortage of facilities and teachers in the public system, and expensive private alternatives that are mostly restricted to urban areas. A particularly strong obstacle to universal primary education in Pakistan has been the inadequate supply of separate schools for girls and the inadequate supply and distribution of schools in rural areas. The costs to parents depend very much on the proximity of "appropriate" schooling.

Information on accessibility to various types of primary schools was collected in the PIHS through a community questionnaire administered in all 300 sample clusters. In Table 5 we show the percentage of children aged 7-14 with access to different types of primary school within one kilometre of the centre of the sample 
cluster. ${ }^{10}$ Our definition of access varies by sex; girls are defined as having access if there is an all-girls school nearby, while for boys access includes the proximity of all-boys as well as coeducational schools. While some girls do attend coed schools, it is more realistic to assume that genuine access for them is equivalent to the existence of an all-girls school nearby. ${ }^{11}$ Because primary school completion often occurs near or after puberty for girls, those attending coed schools are more likely to withdraw before completion and are thus disadvantaged relative to girls in singlesex schools in terms of their chances of completion.

Table 5

Percent of Children Aged 7-14 within 1 Kilometre of Primary School by Type of Facility, Urban-Rural Residence, and Sex*

\begin{tabular}{lccccc}
\hline & \multicolumn{2}{c}{ Urban } & & \multicolumn{2}{c}{ Rural } \\
\cline { 2 - 3 } \cline { 5 - 6 } & Girls & Boys & & Girls & Boys \\
\hline No School & 17.5 & 5.0 & & 21.4 & 9.1 \\
Public Only & 22.2 & 16.3 & & 72.2 & 74.2 \\
Private Only & 10.9 & 16.0 & & 2.1 & 1.8 \\
Both Public and Private & 49.5 & 62.7 & & 4.4 & 14.9 \\
\hline Number of Cases & 1,736 & 1,747 & & 1,646 & 1,743 \\
\hline
\end{tabular}

Source: [PIHS (1991)].

*For girls, only all-girls schools are considered; for boys both coed and all-boys schools are considered.

Looking first at access for urban children, 18 percent of girls do not have access to any school nearby, while 50 percent have access to both private and public schools and 11 percent to private and 22 percent to a public school only. Access is much better for boys; only 5 percent have no school within one kilometre while 63 percent have a choice of a public and private facility nearby. In rural areas, access to schools for girls is poorer still, with 21 percent not within close distance of any school and, among those with access, the majority having access to a public facility only. Boys in rural areas have greater access than girls, but few rural children have access to private schools. Indeed, private schools are predominantly an urban phenomenon. Of course, regardless of residence, all children have the opportunity to

${ }^{10}$ Since the rural cluster is a village we have taken a distance of 1 kilometre or less to depict whether a school is located in the village.

11 This was based on observation and recent field work which indicates that parents generally perceive only on "all girls" school as any meaningful access to girls education. 
attend school somewhere if their parents are willing to have them travel longer distances and can afford to pay. This measure of accessibility captures one aspect of the costs of schooling that is not within parental control.

\section{FAMILY-LEVEL DETERMINANTS OF PRIMARY SCHOOLING}

In Pakistan, which has no compulsory schooling laws [UNESCO (1992)], the decision about children's primary school enrolment, attendance, and the level of educational investment remains within the family. The family is a cohesive unit in Pakistan and, while households can be complex in structure [for instance more than 60 percent of households have more than two related adults; NIPS (1992)], the primary responsibility for a child's support and education rests with his/her biological parents; it is not usually extended to other relatives or older siblings as is common in Sub-Saharan Africa [Lloyd and Gage-Brandon (1992)]. We hypothesise that parents decide for each child about the extent and level of schooling as well as its quality on the basis of present and future anticipated costs and returns. While investments in children will be worthwhile from the parents' point of view if the net return is positive, credit constraints may limit the level of parental investments to what they can afford with disposable cash income. An additional factor in parental decision-making about a particular child's education is likely to be the needs and prospects of their other children.

Educational costs involve both direct monetary outlays for the quality of schooling desired (which may be substantial if an appropriate public school is not located nearby) and opportunity costs from the loss of the child's labour to the family. Furthermore, parents' perceptions of costs may involve other considerations as well. Particularly important in Pakistan are cultural mores that enforce the protection of young women from exposure to the opposite sex once they reach puberty. This would require that girls continuing in school as they approach puberty attend an all-girls school staffed by female teachers and at a minimal distance from home.

Potential perceived returns vary according to each child's ability and future prospects in the labour market and/or the marriage market. Furthermore, these prospects are likely to be strongly influenced by the parents' socio-economic status and level of education, not only because better-educated parents have greater appreciation for the value of education but also because better-off families are better able to help their children get properly situated in a job or a marriage. From the parents' perspective, their returns from investments in a child's schooling will be a function of the likelihood that the child will remit some of the expected returns back to the parents. For this reason, returns to educational investments in girls are likely to be seen by parents as lower than in boys because of their more limited opportunities in the labour market and the near certainty that they will marry out of the family and 
devote their future time and earnings to their husband's family. Perceived returns are also likely to be lower in rural areas, where off-farm employment opportunities, particularly for girls, are limited.

While many of the factors discussed above are expected to explain differences between families in children's educational opportunities, cultural factors increasing the costs and reducing the returns for girls relative to those for the boys lead to inequalities within families. High fertility in the form of numerous siblings is likely to be yet another constraint leading to educational inequalities within families. There are various reasons why we would expect the number of siblings a child has would affect her/his educational chances and levels of investment. The simplest reason is limited parental resources and the relatively high costs of education in Pakistan. This would lead to an advantage for the oldest child, who, during the early schooling years, does not have to compete with other siblings for the family's educational resources. However, as other children are born and budgets remain limited, those children for whom costs are the lowest and expected returns are the highest (i.e., boys and those with greater than average ability) are likely to be favoured. Other factors influencing the relationship between family size and a child's educational chances are household structure and the family's labour needs. A larger family may require a greater immediate contribution from both boys and girls-girls generally helping with domestic chores and child-care and boys helping with the family business or farm. Such pressures would be alleviated if other adults were available to share the work.

Parental schooling decisions are part of a more complex set of family decisions relating to the production and allocation of resources, family building, and household formation. A full simultaneous model of family decision-making over the life-cycle would also include the determinants of family size and household structure, both of which are influenced by many of the same factors as children's schooling decisions. However, in a country where fertility remains close to the natural level (no more than 11 percent of currently married women use modern contraceptive methods), a conditional model of family decision-making in which the family size resulting from past fertility and child mortality becomes a determinant of current schooling decisions seems more realistic. It is extremely unlikely that parents would have planned their families with a view to how many children they would want to have attend school. Furthermore, even if they had, rapid and unexpected economic change (structural adjustment) and demographic change (declines in child mortality) make it unlikely that fertility decisions made at an earlier time under different economic and demographic circumstances would result in exactly the family size that parents would find optimal at a later time. The treatment of actual family size in this analysis as an independent determinant of a child's educational opportunities is based on these considerations-a reasonable approximation at least in 
the short-to-medium run.

\section{Previous Evidence from Pakistan}

Disagreement persists about the primary sources of low enrolments in Pakistan and the large gap between boys and girls. Sabot (1992) attributes low school enrolments in rural areas, particularly of girls, primarily to differences in school supply. Indeed, he derived evidence of a latent demand for girls' schooling from the results of a survey taken by the International Food Policy Research Institute, which shows that gender gaps in schooling and cognitive achievements were primarily attributable to a lack of schools in rural areas. On the other hand, Burney and Irfan (1991) point to the importance of the parental demand factors-in particular parents' education, income, and size of land-holding, rather than the presence of a school in the community-in determining children's schooling levels; in this view, inequality is perpetuated over time as the poverty of the parents gets transmitted to their children. They point out that the growth in school facilities has been three times more rapid than the growth in enrolments. Because of the importance of these factors, they conclude that the failure to enrol children in school cannot be attributed to the insufficiency of schools. While much has been written about schooling in Pakistan, results are difficult to compare given very different samples, methods of measurement, and modes of analysis. The following discussion highlights a few of the major points emerging from a review of that literature.

Using the 1979 Population Labour Force and Migration Survey, two studies looked at poverty impacts on child-schooling and child labour. The first found evidence of lower participation in school among poorer families, a fact which is probably related to demands on children's time [Sathar and Kazi (1987)]. The study confirms that children, particularly boys aged 10-14, are likely to be contributors to family income in the poorest households. This tendency was most marked in rural Pakistan. Also, the proportion of children, again particularly boys 10-14, who were second earners was the highest in poorer households. The second study, utilising the same data, found different sex-specific relationships between child schooling and size of land-holdings [Irfan (1985)]. Male schooling had an inverse relationship with the size of cropped area, and female schooling a positive association. The author argued that the wealth effect is more dominant in the case of females while opportunity costs have a greater influence on male schooling. Household income emerged as a statistically significant determinant of child-schooling, suggesting that the poverty of parents usually gets transmitted to their children.

A study of school dropouts argued that the urban-rural wage differential was a significant factor, and that poverty or low incomes were an important cause of children dropping out and of girls dropping out more frequently than boys [Khan, Siddiqui and Hussain (1986)]. Variables used as proxies for children's domestic 
responsibilities, such as looking after young siblings and animals, were also found to be significant. Time use data from a recent Labour Force Survey in Pakistan (1985-86) provide some indirect substantiation of these differences in income effects by gender. In a study by Alderman and Chishti (1991), the presence of young adolescent girls (aged 10-15) was found to reduce a mother's household labour time (probably because of their assistance with child-care and domestic chores) while the presence of young adolescent boys increased it.

In a study using Asian marriage survey data, father's education had a clearly positive effect on the education level of children, presumably acting as a proxy for permanent household income [King et al. (1986)]. ${ }^{12}$ The same study of Pakistan found no discernible effect on children's schooling of mother's education except in the middle-class urban sample. Families in which women married later tended to provide greater educational opportunities to their children. More recent analyses, however, have suggested that the effect of mother's education by far outweighs that of father's education [Sathar et al. (1988); United Nations (1993)]. The first study, using the Population, Labour Force and Migration Survey of 1979, showed that educated women were not just more likely to have children in school (and that this effect was stronger than that for educated fathers in the sample) but that their daughters were much less likely to be discriminated against vis-à-vis their sons in terms of their schooling chances. This was the case, the second study argued, because there were so few educated women as could only constitute a selective group, one that had much higher aspirations for their children's schooling for both boys and girls.

A recent review of the literature on the household consequences of high fertility in Pakistan [Cochrane, Kozel and Alderman (1990)] found little previous research on fertility and children's education in Pakistan. The most pertinent results cited in that study were from the PIDE/IFPRI urban sample collected since 1986, which showed that the presence of children under age five had a negative and significant effect on the school participation of girls but not of boys. King et al. (1986) had also looked at the birth order and family size effects using the Asian Marriage Survey; they found the relationship with children's educational attainment to be weak because education levels were already so low. By far the most interesting finding was the evidence of strong discrimination between boys and girls in the same families; according to King et al. (1986), if parents treated sons and daughters equally, girls' educational levels would rise by 224 percent in rural Punjab. In another study utilising a small sample of rural households in Pakistan, community and household-level effects appeared much more important than family size effects, but nonetheless gender differentials in family size effects were also apparent [Sathar (1993)].

${ }^{12}$ Irfan (1985) found similar results for father's education. 


\section{RESULTS OF DATA ANALYSIS}

The reproductive-age women in the PIHS sample reported on slightly over 6872 living children aged 7-14 who were resident in the sampled households. These children are the focus of our analysis. For each of these children, we can construct information on all of their living siblings (with the same biological mother) from their mother's birth history as well as information on their educational characteristics from the household survey. ${ }^{13}$

Three dimensions of children's education are analysed sequentially. First, the determinants of a child's school entry are explored. Then, for all children who ever attended school, we analyse the probability that they complete primary school-an important achievement in a country where only 17 percent of the girls and 43 percent of the boys in rural areas (aged 10-14) have done so. Finally we analyse the factors determining the level of parental expenditure on children's primary education for those children currently attending school. Regressions are run separately for boys and girls and by urban/rural residence.

We are aware of certain statistical problems with this approach. With respect to a possible selectivity bias, our analysis of primary school completion is selective of those children who ever attended school; our analysis of educational expenditures is selective of those currently attending school. However, we tested for evidence of selection bias in each case and consistently found it to be statistically unimportant in its effects. ${ }^{14}$ As a result, we prefer to present the simpler uncorrected results, using logit regression for the analysis of school enrolment and primary school completion, and ordinary least squares regression for the analysis of educational expenditures. In order to avoid any statistical problems arising from intra-family correlation that can occur when siblings appear in the same sample, we selected at random one child per mother in each age/sex sub-sample.

${ }^{13}$ An alternative approach would have been to focus on all children aged 7-14 resident in enumerated households. There were two main reasons why we chose to select only those resident children with reproductive-age mothers who provided birth history data: (1) the ages of children were better reported in the birth histories, which were only conducted for women aged 15-49; and (2) each resident child located in the birth histories could be linked with all of his or her living siblings through the biological mother, whether they lived in or outside the household. This would not have been possible for resident children with older mothers who did not provide a full birth history. We are aware that our sample of children is under-representative of children of older ages who have mothers outside the reproductive years. However, we do not suspect that the determinants of education for these children are any different from those included in our sample.

${ }^{14}$ In each case, the probability of selection was estimated using probit regression. Then the estimated hazard rate for selection was included in the relevant regression analysis but was never found to be statistically significant. Because the introduction of the selection correction in the final regression of interest increased the level of multicollinearity and, therefore, increased the standard errors around the estimated coefficients, it was thought preferable to present the simple regressions without the selection correction. 
Table 6 lists the variables used in the multivariate analysis. They can be grouped into child characteristics, parent characteristics, household characteristics, and community characteristics. The child's characteristics include age, number of siblings, and sibling position grouped into four categories. ${ }^{15}$ Parents' characteristics include whether or not the mother had ever attended school and whether the father could read. ${ }^{16}$ Household characteristics include the number of resident male and female adults, whether or not the child's mother was head of the household, whether or not the household head was another adult besides the child's parents, and the level of household consumption measured in deciles. ${ }^{17}$ In addition, we have included a measure of potential demand for child labour that differs by urban/rural areas. In urban areas, we created a dummy variable for whether or not there is a family-business enterprise, and in rural areas we use two dummies to measure the amount of land under cultivation (i.e., one dummy variable for operational-size holdings of under 10 acres and another dummy variable for operational-size holdings exceeding 10 acres).

The community variables include a measure of the accessibility of private and public primary schools ${ }^{18}$ and a dummy variable for three of the four provinces to capture other aspects of supply that may differ by province. For boys, both coed and single-sex schools were included in our access variable, whereas for girls we measured accessibility only in terms of the availability of single-sex schools.

In the following discussion of empirical results, we present the predicted proportions enrolled and completing primary school and the predicted levels of educational expenditure according to the major variables of interest-mother's education, father's literacy, household consumption level, school accessibility, number of siblings, and sibling position. ${ }^{19}$ These predicted values are derived from

${ }^{15}$ The number of siblings and sibling position are never included in the same regression analysis because they overlap.

${ }^{16}$ As explained in note 13 , all children in our sample have mothers who were resident in households where information was collected directly on the education of all household members. Taking into account the possibility that not all children in our sample will have resident fathers (whether because of death, divorce, or separation), we used data on father's literacy that were available for all household members rather than data on the educational attainment of all mothers' current husbands.

${ }^{17}$ This measure was constructed by the World Bank by totalling all household-level consumption (both purchased in the market and produced at home). It places households into deciles in the ascending. order, with decile 1 representing the lowest level of consumption and decile 10 representing the highest.

${ }^{18}$ Information on the existence of and the distance to different types of schools was collected separately in each primary sampling unit using the community questionnaire.

${ }^{19}$ The adjusted percentage for each category of the selected independent variables is derived by first calculating a predicted probability for each individual in the sample based on the logistic regression coefficients and assuming that all individuals fall into each of the categories in turn but retain their actual values with respect to all control variables. The adjusted percentage is then calculated as the mean of the predicted probabilities of all values represent the mean predicted value (expressed as a proportion) for individuals in a particulat category that would result if their distribution with respect to the control variables was the same as that of the entire sample. 
Table 6

List of Variables Included in the Multivariate Analysis

$\mathrm{SCH}$

PSC

EDCOST

\section{Child Characteristics}

\section{AGEY \\ AGE/SQ}

SIBS

SIBRANK

Parents' Characteristics

$\mathrm{MSCH}$

FLIT

MREL 1

MREL 3

TM ADULT

TF ADULT

HHDEC

OPRL 1

OPRL 2

BUSCD

\section{Dependent Variables}

Ever attended school

$$
\text { ( } 1 \text { = yes, } 0 \text { = no) }
$$

Completion of primary school

$$
\text { ( } 1 \text { = yes, } 0=\text { no) }
$$

Total parental expenditure on education, in rupees

\section{Independent Variables}

\section{Household Characteristics}

Child's age

Child's age squared

Number of siblings

Sibship position

$$
(1=1 ; 2=2,3 ; 3=4,5 ; 4=6+)
$$

Mother's school attendance

$$
(1=\text { yes, } 0=\text { no })
$$

Father's literacy

$$
(1=\text { yes, } 0=\text { no) }
$$

Mother household head

$$
\text { ( } 1=\text { yes, } 0=\text { no) }
$$

Neither parent household head

$$
\text { ( } 1=\text { yes, } 0=\text { no) }
$$

Number of male adults (aged $15+$ )

Number of female adults (aged 15+)

Household expenditure in deciles

Household cultivates under 10 acres

$$
\text { ( } 1=\text { yes, } 0=\text { no) }
$$

Household cultivates more than 10 acres

$$
\text { ( } 1=\text { yes, } 0=\text { no) }
$$

Household owns a business

$$
\text { ( } 1=\text { yes, } 0=\text { no) }
$$

\section{Community Characteristics}

\section{PUSH}

PVSH

PUNJAB

SINDH

NWFP
Public school available within 1 kilometre $^{1}$

$$
\text { ( } 1=\text { yes, } 0=\text { no) }
$$

Private school available within 1 kilometre ${ }^{1}$

$$
\text { ( } 1=\text { yes, } 0=\text { no) }
$$

Punjab Province

$$
(1=\text { yes, } 0=\text { no })
$$

Sindh Province

$$
\text { ( } 1=\text { yes, } 0=\text { no })
$$

North West Frontier Province

$$
\text { ( } 1=\text { yes, } 0=\text { no) }
$$


the regression equations that are presented in full in Appendix Tables 1-3, while means of the variables used in the model are presented in Appendix Table 4. This form of presentation is intended to make the results more interpretable and quantitatively meaningful.

\section{School Enrolment}

The most consistently important determinant of whether or not a child ever attends school in Pakistan are parents' education and the level of household consumption. Table 7 presents the predicted probabilities of school enrolment for these and other factors, while Appendix Table 1 presents the full regression results. Mother's schooling and household consumption increase the probability of school enrolment for both sexes in urban and rural areas, and the effects are always highly statistically significant. Education is clearly a normal good and those parents -particularly mothers-who have had some education are more likely to ensure that their children also have that opportunity. As reflected in previous research for Pakistan, mother's education appears to have a larger effect on enrolment than father's literacy, and a larger effect on enrolment of girls than of boys. In rural areas, the predicted proportion of girls enrolled whose mothers are educated is more than twice the proportion of those whose mothers never attended school ( 81 versus 38 percent). Though the difference is not as stark in urban areas, it is still 18 percentage points-twice the differential observed for boys. Household consumption is strongly and positively associated with ever attending school, with differences in enrolment ranging between 30 and 43 percentage points from the lowest to the highest income groups; again the differentials are greater for girls than for boys.

The quality and accessibility of "appropriate" (single-sex) schools for girls is a statistically significant determinant of their school enrolment, particularly in rural areas, where the proportion of girls enrolled is only 31 percent where there is no "appropriate" school nearby and 48 percent where both public and private single-sex options are available within one kilometre. Access to schooling seems to play much less of a role in explaining the differences in school enrolment rates among children living in urban areas.

In an environment where child labour is highly valued, a particular child may indeed have a greater chance of school attendance where there is an abundance of siblings with whom to share family responsibilities. Chernichovsky (1985) found such a relationship in Botswana; the larger the number of children in the household, the more likely that some would attend school. However, this has to be weighed against the fact that, in Pakistan, children's schooling is expensive for most parents in relation to household income. Each additional child is likely to lead to a reduction in per capita consumption, particularly in the short run when a child is able to contribute less to family income than he/she consumes. The net result of these two 
Table 7

Predicted Proportions Ever Enrolled by Selected Individual, Parental, and Community Characteristics (Children Aged 7-14)

\begin{tabular}{|c|c|c|c|c|}
\hline & \multicolumn{2}{|c|}{ Urban } & \multicolumn{2}{|c|}{ Rural } \\
\hline & Girls & Boys & Girls & Boys \\
\hline Mother Ever Enrolled & ** & $* *$ & ** & $\Delta$ \\
\hline Yes & .87 & .91 & .81 & .87 \\
\hline No & .69 & .80 & .38 & .74 \\
\hline Father Literate & $* *$ & * & $* *$ & \\
\hline Yes & .82 & .87 & .57 & .81 \\
\hline No & .71 & .81 & .38 & .74 \\
\hline Household Income Decile & $* *$ & $* *$ & $* *$ & $* *$ \\
\hline Lowest & .42 & .60 & .20 & .56 \\
\hline Middle & .64 & .77 & .35 & .72 \\
\hline Highest & .85 & .90 & .59 & .86 \\
\hline Primary School within 1 & & & & \\
\hline Kilometre: Public/Private & $* *$ & & $* *$ & \\
\hline Yes/Yes & .74 & .84 & .48 & .71 \\
\hline Yes/No & .71 & .82 & .42 & .75 \\
\hline No/Yes & .74 & .79 & .36 & .74 \\
\hline No/No & .71 & .77 & .31 & .77 \\
\hline Number of Siblings & $*$ & * & & \\
\hline 0 & .79 & .83 & .45 & .78 \\
\hline 1 & .78 & .83 & .44 & .77 \\
\hline 2 & .77 & .83 & .43 & .76 \\
\hline 3 & .75 & .83 & .42 & .75 \\
\hline 4 & .74 & .82 & .41 & .75 \\
\hline 5 & .72 & .82 & .40 & .74 \\
\hline 6 & .71 & .82 & .39 & .73 \\
\hline
\end{tabular}

Birth Order

\begin{tabular}{lllll}
1 & .75 & .82 & .45 & .78 \\
$2-3$ & .70 & .83 & $.35 *$ & .72 \\
$4-5$ & .69 & .83 & .34 & .71 \\
$6+$ & .75 & .84 & .38 & $.66^{*}$ \\
\hline
\end{tabular}

Source: [PIHS (1991)].

Note: $\Delta 10 \%$.

*5\%.

$* 1 \%$. 
countervailing forces in Pakistan appears to be that numbers of siblings have relatively little effect on the chances of enrolment, except to a small degree in the case of urban girls. Variation in the number of siblings does not appear to be a major factor influencing the probability of school enrolment. The only significant effects, those for urban girls, are nonetheless small; each additional sibling reduces the probability of enrolment by about one percentage point: 79 percent of the only children are predicted to be enrolled as compared to 71 percent of those with six siblings. Birth-order effects appear potentially more significant in rural areas than sibsize effects, with first-born girls in rural areas having a distinct advantage relative to later-born girls. Rural boys with many older siblings are also at a distinct disadvantage relative to first-born boys.

\section{Primary School Completion}

Once a child enters school, what are the major factors determining her/his chances of completing primary school? Not surprisingly, some of the same factors remain important-in particular the level of household consumption and mother's education (see Table 8 and Appendix Table 2). The fact that a child's mother has ever attended school increases the probability of completion for those ever enrolled by 10-20 percentage points, with the largest effects being for girls in rural areas. Differentials in the predicted completion rates between the highest and the lowest income groups range from 20 percentage points in urban areas to 38 percentage points for rural girls. Interestingly, father's literacy is not an important factor in improving the chances that children will complete the primary level-probably a reflection of the greater role that mothers play at home in helping with homework and creating a supportive environment for learning.

Living near a private school enhances the likelihood that girls will complete the primary level in both urban and rural areas. We interpret these results as a measure of the effect of quality on school completion. Areas with private schools are likely to be those where there is a greater demand for quality education. This may be reflected not only in greater choices for parents but also in improved quality in the public schools.

The presence of additional siblings appears to be a significant factor reducing the probability of primary school completion in urban areas; the effects are not significant in rural areas. The differential in completion rates between the only children and those with six siblings in urban areas is 14 percentage points for boys and 19 percentage points for girls; having six siblings is not an unusual situation for children even in urban areas-38 percent of urban girls have six or more siblings. First-born children-particularly girls-are clearly advantaged relative to younger siblings, who are more likely to drop out of school or progress more slowly. 
Table 8

Predicted Proportions of those Ever Enrolled Completing Primary School by Selected Individual, Parental, and Community Characteristics (Children Aged 10-14)

\begin{tabular}{lccccc}
\hline & \multicolumn{2}{c}{ Urban } & & \multicolumn{3}{c}{ Rural } \\
\cline { 2 - 3 } \cline { 5 - 6 } & Girls & Boys & & Girls & Boys \\
\hline Mother Ever Enrolled & $*$ & $* *$ & & $*$ & $*$ \\
Yes & .66 & .72 & & .58 & .70 \\
No & .56 & .57 & & .38 & .54
\end{tabular}

Father Literate

Yes

No

Household Income Decile

Lowest

Middle

Highest
.58

.59

$*$

.44

.53

.64
.60

.61

*

.47

.56

.67
.35

.40

**

.19

.34

.57

Primary School within 1

Kilometre: Public/Private

Yes/Yes

Yes/No

No/Yes

No/No

Number of Siblings

0

1

2

3

4

5

6
$\Delta$

.61

.54

.62

.54

**

.74

.71

.68

.65

.62

.59

.55
.61

.60

.62

.61

**

.72

.70

.68

.65

.63

.61

.58
.51

.38

.54

.41

.38

.39

.39

.39

.39

.39

.39
.54

.55

.53

.53

.50

.51

.52

.53

.54

.55

.55

Birth Order

\begin{tabular}{lllll}
1 & .67 & .66 & .40 & .54 \\
$2-3$ & $.52 *$ & .57 & .42 & .53 \\
$4-5$ & $.50^{*}$ & .55 & .33 & .60 \\
$6+$ & .52 & $.50 *$ & .36 & .55 \\
\hline
\end{tabular}

Source: [PIHS (1991)].

Note: $\Delta 10 \%$.

$* 5 \%$.

$* 1 \%$. 
From these results, we can identify high fertility as a factor slowing or limiting children's chances of primary school completion in urban areas. Completion rates are likely to be affected by the level of parental educational expenditure in terms of books, tutors, and transportation, as well as by the demands placed on children in the home that may limit their time for school attendance and class preparation. In the urban environment, where private schools are largely available as alternatives, public schools probably set higher standards for their students, thus demanding a greater investment by parents (as was shown in Table 4). In such an environment, large families are more likely to be disadvantageous.

\section{Educational Expenditures}

The level of parents' educational expenditures can be interpreted as a proxy for parental demand for educational quality, if factors such as accessibility, which affect the costs of a given level of quality schooling, are controlled. Table 9 and Appendix Table 3 present the results of ordinary least squares regressions of the likely determinants of educational quality. Again, we find the most important determinants to be mother's education and the level of household consumption, with father's literacy being an important factor in urban areas as well. Children of mothers who have attended school appear to receive 60 to 75 percent more in expenditures in urban areas than the children of unschooled mothers, and the same applies for girls in rural areas. Girls appear to benefit relatively more than boys from having parents with some education, whether it is the father or the mother. Those whose families are in the highest household income bracket receive 2-3 times more than those in the middle decile in urban areas-the differences are slightly smaller but very significant in rural areas as well.

Not surprisingly, the availability of a public school in rural areas leads to reduce educational costs, and the effects are statistically significant for both boys and girls. Conversely, the presence of a private school in rural areas increases average parental expenditures, more notably for boys.

While there appears to be weak evidence in rural areas for a trade-off between numbers of children and parental investment in educational quality, the evidence of such a quality/quantity trade-off is much stronger in urban areas. Levels of expenditure for the only children in urban areas are more than double those for children with six siblings, with slightly larger effects for girls than for boys. The effect of the number of siblings on educational expenditure is primarily an income effect, whereby more siblings reduce per capita consumption and therefore decrease parents' investment in educational quality. Once more, the effect of birth order on educational expenditure is quite strong, especially in urban areas, for both boys and girls; parents tend to spend much more on their older children than on those born later. 


\section{Table 9}

Predicted Parental Expenditures on Primary Schooling by Selected Characteristics (Rupees)

(Children Aged 7-14 Currently Enrolled in a Primary School)

\begin{tabular}{|c|c|c|c|c|}
\hline & \multicolumn{2}{|c|}{ Urban } & \multicolumn{2}{|c|}{ Rural } \\
\hline & Girls & Boys & Girls & Boys \\
\hline Mother Ever Enrolled & ** & $* *$ & ** & \\
\hline Yes & 1081 & 1584 & 534 & 613 \\
\hline No & 614 & 969 & 335 & 441 \\
\hline Father Literate & ** & $* *$ & & \\
\hline Yes & 1039 & 1486 & 342 & 533 \\
\hline No & 647 & 1022 & 350 & 441 \\
\hline Household Income Decile & ** & $* *$ & ** & $* *$ \\
\hline Lowest & -258 & -86 & 115 & 149 \\
\hline Middle & 396 & 716 & 303 & 393 \\
\hline Highest & 1213 & 1718 & 539 & 699 \\
\hline
\end{tabular}

Primary School within 1

Kilometre: Public/Private

Yes/Yes

Yes/No

No/Yes

No/No

Number of Siblings

0

1

2

3

4

5

6
746

721

810

786

**

1314

1195

1074

954

833

713

592
1140

1177

1151

1187

**

1901

1737

1572

1407

1242

1077

911
395

312

532

449

$*$

460

436

413

389

366

342

319
559

405

731

578

509

496

484

471

458

446

433

Birth Order

\begin{tabular}{lcccc}
1 & 933 & 1387 & 378 & 399 \\
$2-3$ & 671 & $960_{\Delta}$ & 361 & $536^{*}$ \\
$4-5$ & $489^{*}$ & $899_{\Delta}$ & 307 & 493 \\
$6+$ & $402^{*}$ & $705^{*}$ & 281 & 411 \\
\hline
\end{tabular}

Source: [PIHS (1991)].

Note: $\Delta 10 \%$.

$* 5 \%$.

** $1 \%$. 


\section{CONCLUSIONS}

In Pakistan, because of substantial school costs and the absence of compulsory schooling laws, the basic decision relating to children's entry into school and completion of the primary level remains within the hands of parents. However, these data show that differentials among children in schooling-particularly in the case of girls-result not just from inequalities among families in education, income, and family size, but also from inadequate educational investments by the government. To complete primary school under current conditions, it appears that a child needs to have parents with education, particularly mothers who have been to school, and an adequate household income. With only a small percentage of school-age children in Pakistan having mothers with any education (28 percent of children aged 7-14 in urban areas and 6 percent in rural areas), or parents with sufficient income, the majority of children do not complete primary school, and the cycle of poverty and unequal opportunity is perpetuated across families and between generations.

The role of public policy in providing adequate school facilities cannot be overstated. Particularly for girls, who are under-represented in school, the accessibility of "appropriate schools" and the availability of quality schools clearly make a difference in their parents' willingness to send them to school. Furthermore, the four provinces appear to offer systematically different educational environments, reflected in significant variation in the provincial educational budgets. Special "drives", such as the one in the Punjab in the late 1980 s to achieve 100 percent enrolment of children in primary school, offer grounds to hope for some radical shifts in the provision of schooling in the near future.

The most pervasive theme emerging from these results is the systematic disadvantage that girls face in Pakistan-a disadvantage which transcends the effect of most other variables. Parents prefer boys to girls [Ali (1989); Sathar (1987)] and appear willing to provide far more for them in terms of schooling. Government policy reflects a similar bias, which is apparent in the fewer girls than boys having access to "appropriate schools". Without government intervention, sex differentials in schooling will lessen only slowly over time, as incomes rise and more mothers have been to school. But given the extent of present inequalities, particularly in rural areas, several generations would be required to reduce them substantially [King et al. (1986)].

In recognition of the importance of human development and to break the cycle of inequality that appears to be perpetuating itself, the Government of Pakistan needs to increase dramatically its financial commitment to primary education in order to (1) increase the number of schools-particularly all-girls schools-in rural areas, (2) improve the quality of the existing schools from the standpoint of efficiency and effectiveness, and (3) reduce the relative costs of attendance for girls through the provision of a more supportive and protective environment and the 
reduction of school expenses. These might include the systematic provision of allgirls schools with female teachers, adjusting school schedules to meet family needs, and safe transportation to and from school. Thus, public policy can play an important role in reducing constraints on families in terms of both financial and social costs, which are often prohibitive if appropriate schooling for girls is located too far from home.

Once the prevalence of primary schooling reaches a substantial enough level, as in urban Pakistan, there is likely to be a "demonstration effect", with an increasing proportion of parents becoming convinced that schooling for children is indeed desirable. Expanding the base of children who attend and complete primary school is central not just to Pakistan's education policy but also to its population policy. Family planning programmes will not succeed in lowering birth rates unless parents find high fertility disadvantageous. If parents become convinced that education is advantageous to their children, they may begin to think of having fewer children. Negative trade-offs between sustained high fertility and children's progress in school have clearly emerged in urban areas, where fertility rates are beginning to decline [NIPS/IRD (1992)]. ${ }^{20}$ Until very recently, there was almost no differential in fertility between urban and rural areas in Pakistan. The perceived disadvantages of high fertility in more modern settings are likely to contribute to the emerging fertility decline.

Furthermore, if girls and boys appear to be equally valued by the state, parents will have less reason to discriminate between them. For fertility decline, the implications of a broader educational access, improved quality, and markedly increased school attendance can be immediate. A change in educational policy that genuinely makes primary schooling "affordable" and attractive to the majority of families for their girls as well as their boys would induce even uneducated parents to seek at least some schooling for all their children. The result is likely to be at least some decline in family size desires, and an increased demand for contraceptive services even within the economic and social environment currently prevailing in rural Pakistan.

${ }^{20}$ The total fertility rate in major cities is 4.7 as compared to 5.6 in rural areas. 
Appendix

Appendix Table 1

Coefficients from Logit Regressions of Attendance in Primary School (Children Aged 7-14)

\begin{tabular}{lcclll}
\hline & \multicolumn{2}{c}{ Urban } & & \multicolumn{2}{c}{ Rural } \\
\cline { 2 - 3 } \cline { 5 - 6 } & Girls & Boys & & Girls & Boys \\
\hline Child Characteristics & & & & & \\
AGE & .47 & .47 & & -.09 & $1.03^{*}$ \\
AGESQ & -.02 & -.02 & & -.01 & $-.04^{*}$ \\
SIBS & $-.09^{*}$ & -.01 & & -.06 & -.05 \\
& & & & & \\
Parents' Characteristics & & & & & \\
MSCH & $1.28^{* *}$ & $.97^{* *}$ & & $2.35^{* *}$ & $1.04 \Delta$ \\
FLIT & $.77^{* *}$ & $.51_{\Delta}$ & & $.97^{* *}$ & .48 \\
& & & & \\
Household Characteristics & & & & & \\
MREL 1 & .36 & .49 & & -.06 & -.55 \\
MREL 3 & $-.47 \Delta$ & $-.56^{*}$ & & -.01 & $-.42 \Delta$ \\
TM ADULT & -.07 & $.15 \Delta$ & & $.13 \Delta$ & -.10 \\
TF ADULT & .03 & .04 & & -.07 & $.14 \Delta$ \\
HHDEC & $.29 * *$ & $.23^{* *}$ & & $.24^{* *}$ & $.20^{* *}$ \\
OPRL 1 & - & - & & $-.97^{* *}$ & -.00 \\
OPRL 2 & - & - & $-.75^{*}$ & $-.77^{* *}$ \\
BUSCD & .16 & .06 & & - & - \\
& & & &
\end{tabular}

Community Characteristics

$\begin{array}{lcccc}\text { PUSH } & -.05 & .36 & .61^{* *} & -.18 \\ \text { PVSH } & .20 & .15 & .27 & -.23 \\ \text { PUNJAB } & 2.31^{* *} & 1.55^{* *} & 1.46^{* *} & 1.41^{* *} \\ \text { SINDH } & 1.26^{* *} & .61^{*} & .47 & .15\end{array}$

North West Frontier

\begin{tabular}{lccrc}
\multicolumn{1}{c}{ Province } & $.91 * *$ & $1.24 * *$ & .42 & $1.00^{* *}$ \\
\hline Number of Cases & 1,056 & 1,061 & 1,025 & 1,070 \\
MEAN SCH & .73 & .82 & .40 & .74 \\
\hline
\end{tabular}

Source: [PIHS (1991)].

Note: $\Delta \mathrm{p} \leq .1$.

" $p \leq .05$.

$* \mathrm{p} \leq .01$. 
Appendix Table 2

Coefficients from Logit Regressions of Primary School Completion (Children Aged 10-14 Ever Enrolled)

\begin{tabular}{llllll}
\hline & \multicolumn{2}{c}{ Urban } & & \multicolumn{2}{c}{ Rural } \\
\cline { 2 - 3 } \cline { 5 - 6 } & Girls & Boys & & Girls & Boys \\
\hline
\end{tabular}

Child Characteristics

AGE

AGESQ

SIBS
1.58

$-.04$

$-.18 * *$

$.54 *$

$-.05$

FLIT

Parents' Characteristics
$\mathrm{MSCH}$

Household Characteristics

MREL 1

MREL 3

TM ADULT

TF ADULT

HHDEC

OPRL 1

OPRL 2

BUSCD

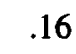

$-.51$

$-.08$

.17

$.11^{*}$

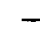

$-$

$-.10$
$7.91 * *$

$-.30 * *$

$-.14 *$

$.88 * *$

$-.03$
2.72

$-.09$

.01

3.29*

$-.11 \Delta$

.05

\section{Community Characteristics}

PUSH

PVSH

PUNJAB

SINDH

-.01
$.38 \Delta$
.18
-.25

$-.25$
$-.27$

$-.19$

$-.08$

.05

$.12 *$

$-$

$-$

$-.06$
$1.10^{*}$

$-.26$ .28

North West Frontier

\begin{tabular}{lrrrr} 
Province & -.16 & $.90^{*}$ & 1.03 & -.49 \\
\hline Number of Cases & 503 & 617 & 249 & 558 \\
MEAN PSC & .58 & .61 & .39 & .55 \\
\hline
\end{tabular}

Source: [PIHS (1991)].

Note: $\Delta \mathrm{p} \leq .1$.

$* p \leq 05$.

$-p \leq .01$. 
Appendix Table 3

Coefficients from Ordinary Least Square Regressions of Educational Expenditure (Children Aged 7-14)

\begin{tabular}{llllll}
\hline & \multicolumn{2}{c}{ Urban } & & \multicolumn{2}{c}{ Rural } \\
\cline { 2 - 3 } \cline { 5 - 6 } & Girls & Boys & & Girls & Boys \\
\hline
\end{tabular}

Child Characteristics

$\begin{array}{lcccc}\text { AGE } & 23.5 & 124.9 & 9.5 & 342.0^{*} \\ \text { AGESQ } & -3.0 & -2.3 & 1.1 & -13.7^{*} \\ \text { SIBS } & -120.3^{* *} & -165.0^{* *} & -23.4^{*} & -12.6\end{array}$

Parents' Characteristics

$\begin{array}{lrrrr}\text { MSCH } & 466.7^{* *} & 614.8^{* *} & 199.2^{* *} & 172.7 \\ \text { FLIT } & 392.7^{* *} & 463.8^{* *} & -8.7 & 92.7\end{array}$

Household Characteristics

MREL 1

MREL 3

TM ADULT

TF ADULT

HHDEC

OPRL 1

OPRL 2

BUSCD
193.1

$-91.2$

28.7

$-97.6 \Delta$

$163.5 * *$

$-$

$-$

16.5
437.6

$-485.0^{*}$

$-21.5$

35.7

$200.4 * *$

$-$

$-$

$-14.3$

\section{Community Characteristics}

$\begin{array}{lrrrr}\text { PUSH } & -64.6 & -9.9 & -137.0^{*} & -171.6^{*} \\ \text { PVSH } & 24.5 & -36.8 & 83.3 & 153.5^{*} \\ \text { PUNJAB } & 125.2 & 235.4 & 2.8 & -264.5^{*} \\ \text { SINDH } & 396.0 & 351.4 & -73.8 & -377.9^{* *}\end{array}$

North West Frontier

\begin{tabular}{lcccc}
\multicolumn{1}{c}{ Province } & -58.1 & 184.3 & -142.4 & $-561.1^{* *}$ \\
\hline Number of Cases & 524 & 592 & 295 & 556 \\
Mean Ed. Cost & 755 & 1151 & 350 & 451 \\
Adjusted R Squared & .30 & .26 & .16 & .20 \\
\hline
\end{tabular}

Source: [PIHS (1991)].

Note: $\Delta \mathrm{p} \leq .1$.

$* p \leq .05$.

${ }^{* *} \mathrm{p} \leq .01$. 
Appendix Table 4

Means and Average Proportions for All Variables Used in the Regression Analysis (Children Aged 7-14)

\begin{tabular}{|c|c|c|c|c|}
\hline & \multicolumn{2}{|c|}{ Urban } & \multicolumn{2}{|c|}{ Rural } \\
\hline & Girls & Boys & Girls & Boys \\
\hline
\end{tabular}

\section{Child Characteristics}

$\begin{array}{lrrrr}\text { AGE } & 10.08 & 10.15 & 10.00 & 9.90 \\ \text { AGESQ } & 106.80 & 108.20 & 106.30 & 103.40 \\ \text { SIBS } & 5.03 & 4.89 & 5.04 & 4.97\end{array}$

Parents' Characteristics

MSCH

FLIT
.29

.28
.28

.28
.07

.11
.06

.11

\section{Household Characteristics}

MREL 1

.03

.03

.02

.02

MREL 3

.14

.14

.17

.18

TM ADULT

2.19

2.18

2.20

2.18

TF ADULT

2.04

2.02

2.19

2.11

HHDEC

OPRL 1

7.28

7.24

6.13

5.95

OPRL 2

BUSCD

- $\quad-$

.07

.08

.46

.47

Community Characteristics

PUSH

PVSH

PUNJAB

SINDH
.72

.60

.49

.27
.79

.77

.06

.44

.28
.89

.17

.49

.26

North West Frontier

\begin{tabular}{lcccc}
\multicolumn{1}{c}{ Province } & .15 & .17 & .20 & .19 \\
\hline SCH & .73 & .78 & .40 & .74 \\
PSC $^{*}$ & .60 & .61 & .43 & .53 \\
EDCOST & 868.8 & 1041.4 & 376.9 & 431.3 \\
\hline Number of Cases & 1736 & 1747 & 1646 & 1743
\end{tabular}

Source: [PIHS (1991)].

*These means are computed for 10-14 year-olds who have ever attended primary school. 


\section{REFERENCES}

Alderman, Harold, and Salim Chishti (1991) Simultaneous Determination of Household and Market-oriented Activities of Women in Rural Pakistan. In T. Paul Schultz (ed) Research in Population Economics. Vol. 7. Greenwich, Connecticut: JAI Press, Inc. 245-265.

Alderman, Harold, Jere R. Behrman, Shahrukh R. Khan, David Ross and Richard Sabot (1992) Public Schooling Expenditures in Rural Pakistan: Efficiently Targeting Girls and a Lagging Region. Paper presented at the World Bank conference on the Incidence and Targeting of Public Expenditure, June.

Ali, Syed Mubashir (1989) Does Son Preference Matter? Journal of Biosocial Science 21:4 399-408.

Anand, Sudhir, and Martin Ravallion (1993) Human Development in Poor

Countries: On the Role of Private Incomes and Public Services. Journal of Economic Perspectives 7:1 133-150.

Burney, Nadeem A., and Mohammad Irfan (1991) Parental Characteristics, Supply of Schools, and Child School Enrolment in Pakistan. The Pakistan Development Review 30:1 21-62.

Caldwell, John C. (1980) Mass Education as a Determinant of the Timing of

Fertility Decline. Population and Development Review 6:2 225-251.

Chernichovsky, Dov (1985) Socioeconomic and Demographic Aspects of School

Enrolment and Attendance in Rural Botswana. Economic Development and Cultural Change 33:2 319-332.

Cochrane, Susan, Valerie Kozel and Harold Alderman (1990) Household Consequences of High Fertility in Pakistan. Washington, D. C.: World Bank. (Discussion Paper No. 111.)

Irfan, Mohammad (1985) Poverty and Household Demographic Behaviour in Pakistan-Insights from PLM Survey 1979. Islamabad: Pakistan Institute of Development Economics. (Studies in Population, Labour Force and Migration, Project Report No. 11.)

Jimenez, Emmanuel, and Jee-Peng Tan (1985) Educational Development in

Pakistan: The Role of User Charges and Private Education. Washington, D. C.:

World Bank. (Discussion Paper, Education and Training Series.)

Khan, Shahrukh R. (1991) South Asia. In Elizabeth M. King and M. Anne Hill (eds)

Women's Education in Developing Countries: Barriers, Benefits and Policy.

Washington, D. C.: World Bank. 179-208. (PHREE Background Paper Series.) Khan, Shahrukh R., Naushin Mahmood and Rehana Siddiqui (n.d.) An Analysis of School Level Enrolments, Drop Outs and Output in Pakistan: Supply and Demand Side Considerations (1970-71-1982-83). Islamabad: Pakistan Institute of Development Economics. Table IV-I, p. 48. (Mimeographed.) 
Khan, Shahrukh R., Rehana Siddiqui and Fazal Hussain (1986) An Analysis of School Level Drop-out Rates and Output in Pakistan. Islamabad: Pakistan Institute of Development Economics. (Research Reports Series No. 149.)

Khawja, Sarfraz (1989) Basic Education for All; Policies and Plans Review, 1947-1989. Islamabad.

King, Elizabeth M. et al. (1986) Changes in the Status of Women Across Generations in Asia. Santa Monica, California: Rand Corporation. (Rand Report R-3399-RF.)

Lloyd, Cynthia B., and Anastasia J. Gage-Brandon (1992) Does Sibsize Matter? The Implications of Family Size for Children's Education in Ghana. Population Council Research Division. (Working Paper No. 45.)

Mahmood, Naushin, and G. M. Zahid (1992) Measuring the Education Gap in Primary and Secondary Schooling in Pakistan. The Pakistan Development Review 31:4 729-740.

NIPS/IRD (1992) Pakistan Demographic and Health Survey 1990-91. Islamabad: National Institute of Population Studies/Columbia, Maryland: IRD/Macro International.

Psacharopoulos, G. (1985) Returns to Education: A Further International Update and Implications. Journal of Human Resources 20: Fall 583-604.

Rodriguez, G., and R. Aravena (1991) Socio-Economic Factors and the Transition to Low Fertility in Less Developed Countries: A Comparative Analysis. In Proceedings of the Demographic and Health Surveys World Conference. IRD/Macro International, Columbia, Maryland.

Sabot, Richard H. (1992) Human Capital Accumulation in Post Green Revolution Rural Pakistan: A Progress Report. The Pakistan Development Review 31:4 449-490.

Sathar, Zeba (1987) Sex Differentials in Mortality: A Corollary of Son Preference? The Pakistan Development Review 26:4 555-568.

Sathar, Zeba (1993) Micro-consequences of High Fertility: The Case of Child Schooling in Rural Pakistan. In Cynthia B. Lloyd (ed) Fertility, Family Size, and Structure: Consequences for Families and Children. New York: The Population Council. 415-444.

Sathar, Zeba, and Shahnaz Kazi (1987) Variations in Demographic Behaviour by Levels of Living in Pakistan. Genus 43: 113-136.

Sathar, Zeba et al. (1988) Women's Status and Fertility Change in Pakistan. Population and Development Review 4:3 415-432.

Schultz, T. Paul (1991) Returns to Women's Education. In Elizabeth M. King and M. Anne Hill (eds) Women's Education in Developingt Countries: Barriers, Benefits and Policy. Washington, D. C.: World Bank. 43-78. (PHREE Background Paper Series.) 
Siddiqui, S. A. (1991) Primary Education in Pakistan. Paper presented at the Seminar on Eighth Five Year Plan (1993-98). Planning Commission, Government of Pakistan, Islamabad, January.

Summers, L. H. (1992) Investing in All the People. The Pakistan Development Review 31:4 367-404.

UNDP (1990) Human Development Report. New York: Oxford University Press. UNESCO (1992) Statistical Yearbook, 1992. Paris.

United Nations (1987) Fertility Behavior in the Context of Development: Evidence from the World Fertility Survey. New York.

United Nations (1993) Women's Status and Fertility Change in Pakistan: Recent Evidence. New York: United Nations, Department of Economic and Social Information and Policy Analysis.

World Bank (1992) PIHS: Final Results, 1991. Washington, D. C.: World Bank. 